\title{
VOTING ON INCOME REDISTRIBUTION:
}

\section{HOW A LITTLE BIT OF ALTRUISM CREATES TRANSITIVITY}

\author{
DONALD WITTMAN \\ ECONOMICS DEPARTMENT \\ UNIVERSITY OF CALIFORNIA \\ SANTA CRUZ \\ $\underline{\text { wittman@ucsc.edu }}$
}

\begin{abstract}
We consider an election that is solely concerned with redistribution of income. It is well known that when voters are selfish, there is no political equilibrium. We consider the case where voters are modestly altruistic. We demonstrate that modest altruism results in a unique political equilibrium. We also provide an explanation for why voters are much more altruistic than individuals acting alone.
\end{abstract}

Keywords: political income redistribution, altruism, transitivity

JEL classification: D7, D64, D63 


\title{
WHEN DOES ALTRUISM OVERCOME THE INTRANSITIVITY OF INCOME REDISTRIBUTION?
}

\author{
DONALD WITTMAN* \\ ECONOMICS DEPARTMENT \\ UNIVERSITY OF CALIFORNIA
}

SANTA CRUZ

Self-interest may work well in the economic sphere, but it wrecks havoc in the political sector. The ability of a majority to redistribute wealth from the minority to itself is ever present in a pure democratic system. When people are selfish there is no permanent majority and intransitivity arises. With each election, a totally different distribution of wealth is possible. Can a modest degree of altruism prevent such centrifugal forces? Here we answer in the affirmative by showing that a certain level of altruism creates the conditions for stability and equality. In the process, we also show why people are more altruistic when they vote than when they act individually. Essentially, public policy may tie others into being generous so that a small tax cost to any particular voter may result in a large emotional benefit to the taxpayer because so many deserving poor are subsidized.

More than forty years ago, Ward (1961) demonstrated that majority rule is intransitive when selfish voters vote on income distribution. The following simple example will illustrate:

\begin{tabular}{|l|l|l|l|}
\hline & A & B & C \\
\hline$X$ & 33.33 & 33.33 & 33.33 \\
\hline$Y$ & 50 & 40 & 0 \\
\hline$Z$ & 0 & 45 & 10 \\
\hline
\end{tabular}

A majority prefers allocation $Y$ to allocation X (A prefers 50 over 33.33 and B prefers 40 over 33.33). In turn, a majority of voters (this time $\mathrm{B}$ and $\mathrm{C}$ ) prefer $\mathrm{Z}$ to $\mathrm{Y}$. But a majority of voters (A and $\mathrm{C}$ ) prefer $\mathrm{X}$ to $\mathrm{Z}$. 
What degree of altruism is necessary to overcome this divisiveness of wealth distribution? To answer this question, we first consider a reasonable altruism function that yields Pareto optimal results. ${ }^{1}$ We then show the conditions for this utility function to lead to a majority-rule equilibrium.

\section{THE THEORETICAL MODEL}

We assume that voters have the following utility function:

$\mathrm{U}^{\mathrm{i}}(\mathrm{X})=\mathrm{U}^{\mathrm{i}}\left(\mathrm{x}_{1}, \mathrm{x}_{2}, \ldots \mathrm{x}_{\mathrm{N}}\right)=\mathrm{x}_{\mathrm{i}}+\mathrm{B} \Sigma \mathrm{x}_{\mathrm{j}} / \mathrm{N}-\mathrm{BC} \Sigma\left(\mid \mathrm{x}_{\mathrm{j}}-\overline{\mathrm{x}} \mathrm{l}\right) / \mathrm{N}$.

$\mathrm{x}_{\mathrm{i}}$ is i's utility from income, $\mathrm{x}_{\mathrm{i}} \geq 0$. This is the self-interest component. $\mathrm{B}>0$ is the voter's altruism weight. The larger $\mathrm{B}$ is, the less the voter weights his/her own income. $\Sigma \mathrm{x}_{\mathrm{j}} / \mathrm{N}$ is average income. Thus, B $\Sigma \mathrm{x}_{\mathrm{j}} / \mathrm{N}$ is the utility that the voter gets from high average income. $\Sigma\left(\left|\mathrm{x}_{\mathrm{j}}-\overline{\mathrm{x}}\right|\right) / \mathrm{N}$ is the average absolute deviation in income. The voter suffers a utility loss from an unequal distribution of income. $\mathrm{C}>0$ is the weight a person places on the distribution of income relative to average income.

There are, of course, a great many possible altruism functions. The advantage of this function is that it is readily understood and, because of its linearity, easy to calculate. One possible disadvantage of the formulation is that it may go against notions of fair distribution. For example, the formula says that person i would be indifferent between case (A) where $\mathrm{j}$ 's income was two units below the average income and k's income was the average income and case (B) where both j's and k's income were 1 unit below average. This can be easily remedied by adding a small cost to extreme variation in incomes. Alternatively, one can argue that with linear utility of income, the loss due to unequal distribution should be linear, as well. In any event, one could choose other functions with other more complicated restrictions and obtain parallel propositions to those presented here.

PROPOSITION 1: If $\mathrm{C} \leq .5$, the altruism measure is positively associated with Pareto improvements. That is, an increase in any voter's income, holding other voters' income constant, will result in a greater welfare measure.

\footnotetext{
* I would like to thank the participants at the Villa Colombella conference in Parma for inspiration and helpful suggestions.

${ }^{1}$ Hochman and Rodgers (1969) consider Pareto optimal redistribution but do not consider voting.
} 
Proof:

For any given total income, the greatest welfare loss occurs when all the income is allocated to one person. Therefore, we only need to concentrate on this extreme case for the proof. Suppose that all the income goes to $\mathrm{j}$ and that the remaining $\mathrm{N}-1$ voters receive 0 . Then the total income is $\mathrm{x}_{\mathrm{j}}$ and average income is $x_{j} / N$. The altruism component for $i$ is then:

$B x_{j} / N-B C(N-1) 10-x_{j} / N I / N-B C I x_{j}-x_{j} / N I / N$

$=(\mathrm{B} / \mathrm{N})[1-\mathrm{C}(\mathrm{N}-1) / \mathrm{N}-\mathrm{C}(\mathrm{N}-1) / \mathrm{N}] \mathrm{x}_{\mathrm{j}}=(\mathrm{B} / \mathrm{N})[1-2 \mathrm{C}(\mathrm{N}-1) / \mathrm{N}] \mathrm{x}_{\mathrm{j}}$

Thus if $\mathrm{C} \leq .5$, an increase in $\mathrm{x}_{\mathrm{j}}$ results in an increase in the altruism measure. That is, a Pareto improvement results in a higher welfare measure, as well.

q.e.d.

Next, we show that a voting equilibrium exists.

PROPOSITION 2: If $\mathrm{BC}>\mathrm{N} /(\mathrm{N}+1)$, then a voting equilibrium exists with all voters having the same income.

Proof:

Let $\mathrm{X}=\mathrm{x}_{1}, \mathrm{x}_{2}, \ldots \mathrm{x}_{\mathrm{N}}$ be a distribution of income among the $\mathrm{N}$ voters.

Let $\mathrm{X}^{*}=\mathrm{x}^{*}{ }_{1}, \mathrm{X}_{2}{ }_{2}, \ldots \mathrm{X}_{\mathrm{N}}$ be an equal division of the maximal total wealth, $\mathrm{Y}$.

That is, $x^{*}{ }_{i}=x^{*}{ }_{j}=Y / N$.

When the distribution of income is identical for all voters, we will denote the utility of a voter by $\mathrm{U}\left(\mathrm{X}^{*}\right)=\mathrm{U}^{\mathrm{E}}$, where e stands for equitable and efficient. We do not use a superscript $\mathrm{i}$ in this case since all the voters have identical utility functions and identical incomes.

Let $\mathrm{X}_{-\mathrm{i}}=\mathrm{x}_{1}, \mathrm{x}_{2}, \ldots \mathrm{x}_{\mathrm{i}-1}, \mathrm{x}_{\mathrm{i}+1}, \quad \mathrm{x}_{\mathrm{N}}$. That is, $\mathrm{X}_{-\mathrm{i}}$ is the distribution of income to the $\mathrm{j}$ voters not including voter $\mathrm{i}$. 
We will concentrate on the case where $\Sigma \mathrm{x}_{\mathrm{j}}=\mathrm{Y}$. If we can show that $\mathrm{X}^{*}$ is a Condorcet winner against all $\mathrm{X}$ such that $\Sigma \mathrm{x}_{\mathrm{j}}=\mathrm{Y}$, then $\mathrm{X}^{*}$ is a Condorcet winner against all $\mathrm{X}$ such that $\Sigma \mathrm{x}_{\mathrm{j}} \leq$ Y.

For a given total income, a necessary condition for the distribution $\mathrm{X}$ to be preferred by a majority to $\mathrm{X}^{*}$ is that the median income voter under $\mathrm{X}$ must have higher income than under $\mathrm{X}^{*}$. This is because $X^{*}$ beats all other $X$ on distributional grounds; therefore, the median voter will only prefer $\mathrm{X}$ over $\mathrm{X}^{*}$ if she receives a higher income under $\mathrm{X}$ than under $\mathrm{X}^{*}$.

Furthermore, for a given $\mathrm{x}_{\mathrm{i}}$, every voter $\mathrm{i}$ will prefer that $\mathrm{X}_{-\mathrm{i}}$ is distributed as evenly as possible. This means that there are only $(\mathrm{N}+1) / 2$ voters in the winning coalition and that the median voter (the one who has the least to gain) prefers that none of the other voters in the winning coalition get more than the median voter. That is, the distribution that has the best chance of beating $\mathrm{X}^{*}$ is the one in which $(\mathrm{N}+1) / 2$ voters in the winning coalition $(\mathrm{W})$ each get $\mathrm{x}_{\mathrm{W}}>\mathrm{Y} / \mathrm{N}$, and the $(\mathrm{N}-1) / 2$ voters in the losing coalition $(\mathrm{L})$ each get $\mathrm{x}_{\mathrm{L}}=\left[\mathrm{Y}-\mathrm{X}_{\mathrm{W}}(\mathrm{N}+1) / 2\right] /[(\mathrm{N}-1) / 2]{ }^{2}$

Plugging this into our formula $\mathrm{U}^{\mathrm{i}}=\mathrm{x}_{\mathrm{i}}+\mathrm{B} \mathrm{Y} / \mathrm{N}-\mathrm{BC} \Sigma \mid \mathrm{x}_{\mathrm{j}}-\overline{\mathrm{x}} \mathrm{l} / \mathrm{N}$, we get:

$$
\begin{aligned}
\mathrm{U}^{\mathrm{W}}= & \mathrm{x}_{\mathrm{W}}+\mathrm{B} \mathrm{Y} / \mathrm{N}-\left.\mathrm{BC}\right|_{\mathrm{W}}-\mathrm{Y} / \mathrm{Nl}(\mathrm{N}+1) / 2 \mathrm{~N} \\
& -\mathrm{BC} \mid \mathrm{Y} / \mathrm{N}-\left[\mathrm{Y}-\mathrm{x}_{\mathrm{W}}(\mathrm{N}+1) / 2\right] /[(\mathrm{N}-1) / 2] \mathrm{l}(\mathrm{N}-1) / 2 \mathrm{~N} .
\end{aligned}
$$

Since BC $\sum \mid x_{\mathrm{i}}-\overline{\mathrm{x}} \mathrm{l} / \mathrm{N}$ is based on deviations from the mean, we know that the sum of positive deviations from the mean (the last expression on the first line) is equal to the sum of negative deviations from the mean (the second line). Therefore, we ignore the second line and just multiply the last expression of the first line by two and get:

$$
\begin{aligned}
\mathrm{U}^{\mathrm{W}}= & \mathrm{x}_{\mathrm{W}}+\mathrm{B} \mathrm{Y} / \mathrm{N}-\mathrm{BC}\left[\mathrm{x}_{\mathrm{W}}-\mathrm{Y} / \mathrm{N}\right](\mathrm{N}+1) / \mathrm{N} \\
& \mathrm{X}^{*} \text { is a Condorcet winner if } \mathrm{U}^{\mathrm{W}} \text { is less than } \mathrm{U}^{\mathrm{E}}=\mathrm{U}\left(\mathrm{X}^{*}\right)=\mathrm{Y} / \mathrm{N}+\mathrm{B} \mathrm{Y} / \mathrm{N} \text {. }
\end{aligned}
$$

\footnotetext{
2 Because the welfare function is based on absolute deviations, the $(\mathrm{N}-1) / 2 \mathrm{~N}$ losers need not share the loss equally. This possibility does not change the analysis.
} 


$$
\begin{aligned}
\mathrm{U}^{\mathrm{E}}-\mathrm{U}^{\mathrm{W}} & =\mathrm{Y} / \mathrm{N}-\mathrm{x}_{\mathrm{W}}+\mathrm{BC}\left[\mathrm{x}_{\mathrm{W}}-\mathrm{Y} / \mathrm{N}\right](\mathrm{N}+1) / \mathrm{N} \\
& =(\mathrm{Y} / \mathrm{N})[1-\mathrm{BC}(\mathrm{N}+1) / \mathrm{N}]-\mathrm{x}_{\mathrm{W}}[1-\mathrm{BC}(\mathrm{N}+1) / \mathrm{N}]
\end{aligned}
$$

$\mathrm{x}_{\mathrm{W}}>\mathrm{Y} / \mathrm{N}$. Therefore, if $\mathrm{BC} \geq \mathrm{N} /(\mathrm{N}+1), \mathrm{X}^{*}$ is a Condorcet winner.

q.e.d.

PROPOSITION 3: If $\mathrm{BC}<\mathrm{N} /(\mathrm{N}+1)$, then majority voting is intransitive.

Proof:

By the last equality in the above theorem, $\mathrm{X}^{*}$ will lose to another distribution. So suppose that we have an $X \neq X^{*}$. Let $x_{m}$ be the median income.

If $x_{m} \leq Y / N$, then $X^{*}$ will be preferred by a majority of voters to $X .{ }^{3}$ The voters whose incomes were originally strictly less than $\mathrm{Y} / \mathrm{N}$ will be better off on both selfish and altruistic grounds if everyone is at $\mathrm{Y} / \mathrm{N}$. Those who were originally at $\mathrm{Y} / \mathrm{N}$ are indifferent on selfish grounds but are strictly better off because their altruism component leads them to prefer a universal income of $\mathrm{Y} / \mathrm{N}$. Since $\mathrm{x}_{\mathrm{m}} \leq \mathrm{Y} / \mathrm{N}$, there are a majority of voters who fit these two categories. So a majority of voters will vote for $\mathrm{Y} / \mathrm{N}$.

Next, suppose that $x_{m}>Y / N$. Let $n$ be the voter with the highest income (if there is a tie for the highest income, arbitrarily choose one of these voters as voter $n)$. Take $x_{n}-Y / N$ from $x_{n}$ and distribute this amount to those voters whose incomes are initially below $\mathrm{Y} / \mathrm{N}$ in such a way that none of these voters have more than $\mathrm{Y} / \mathrm{N}$ after the redistribution. This is possible since the amount of income below $\mathrm{Y} / \mathrm{N}$ equals the amount of income above $\mathrm{Y} / \mathrm{N}$. This method increases the utility of all voters except, possibly, voter $\mathrm{n}$ because the altruism component is increased for everyone and only one voter, $\mathrm{n}$, is hurt on the selfish component. Indeed one or more voters may benefit on the selfish dimension as well. Therefore, $\mathrm{N}-1$ voters will vote for this redistribution.

\footnotetext{
3 This cannot be the same $\mathrm{X}$ that beat $\mathrm{X} *$ in the first place because there the median voter received more than the average.
} 
Therefore, every unequal allocation loses to some other allocation and the equal allocation loses to some unequal allocation. Thus, we have intransitivity.

q.e.d

Thus, we see that some altruism is necessary for majority rule voting on income distribution to be stable.

So far, we have analyzed the case where all of the voters are equally altruistic. It is insightful to ask what happens if there is a subset, $\mathrm{S}$, of purely selfish voters. Clearly, if this subset is a majority, then intransitivity will again arise because this majority will vote to give itself more than the average income. But there is always another distribution that will take away the excess "pie" from the $\mathrm{K}$ member of this majority who received the most pie and redistribute this amount to the other members of the majority and the $\mathrm{K}$ people who originally received less than the average. A majority of voters will prefer this second distribution to the original distribution because this majority is better off on both selfish and altruistic grounds if they are so inclined. The logic can repeat itself and we are on the way to intransitivity.

We will next consider the case where the number of purely selfish people is $\mathrm{S}<(\mathrm{N}+1) / 2$ and the remaining $\mathrm{N}-\mathrm{S}$ voters are altruistic.

PROPOSITION 4: Suppose that $\mathrm{S}<(\mathrm{N}+1) / 2$. If $\mathrm{BC}>\mathrm{N} /[(\mathrm{N}+1)-2 \mathrm{~S}]$, then a voting equilibrium exists with all voters having the same income.

Proof:

Consider the case where all $\mathrm{S}$ selfish individuals receive $\mathrm{x}_{\mathrm{W}}>\mathrm{Y} / \mathrm{N}$ and $[(\mathrm{N}+1) / 2]-\mathrm{S}$ altruistic people receive $D x_{W} \geq Y / N$. When given the choice between $Y / N$ and $x_{W}>Y / N$, all of the $\mathrm{S}$ selfish individuals will vote for the distribution that gives them $\mathrm{x}_{\mathrm{W}}$. In order for the lucky $[(\mathrm{N}+1) / 2]-\mathrm{S}$ altruistic individuals to vote for this distribution, as well, the following must hold:

$$
\begin{aligned}
\mathrm{U}^{\mathrm{W}}= & \mathrm{Dx}_{\mathrm{W}}+\mathrm{B} \mathrm{Y} / \mathrm{N}-\left.\mathrm{BC}\right|_{\mathrm{x}_{\mathrm{W}}}-\mathrm{Y} / \mathrm{N}|\mathrm{S} / \mathrm{N}-\mathrm{BC}| \mathrm{Dx}_{\mathrm{W}}-\mathrm{Y} / \mathrm{Nl}[(\mathrm{N}+1) / 2-\mathrm{S}] / \mathrm{N} \\
& -\mathrm{BC} \mid \mathrm{Y} / \mathrm{N}-\left[\mathrm{Y}-\mathrm{x}_{\mathrm{W}} \mathrm{S}-\mathrm{D} \mathrm{x}_{\mathrm{W}}[(\mathrm{N}+1) / 2-\mathrm{S}] /[(\mathrm{N}-1) / 2] \mathrm{I}(\mathrm{N}-1) / 2 \mathrm{~N}\right. \\
> & \mathrm{U}^{\mathrm{E}}=\mathrm{Y} / \mathrm{N}+\mathrm{B} \mathrm{Y} / \mathrm{N} .
\end{aligned}
$$


Again, we will take advantage of the fact that the sum of positive deviations from the average (the last two expressions in the first line) equals the sum of negative deviations from the average (the second line) by dropping the second line and multiplying the last two expressions of the first line by two. Hence,

$\mathrm{U}^{\mathrm{W}}=\mathrm{Dx}_{\mathrm{W}}+\mathrm{B} \mathrm{Y} / \mathrm{N}-2 \mathrm{BC} \mathrm{Ix}_{\mathrm{W}}-\mathrm{Y} / \mathrm{Nl} \mathrm{S} / \mathrm{N}-2 \mathrm{BC} \mid \mathrm{Dx} \mathrm{x}_{\mathrm{W}}-\mathrm{Y} / \mathrm{Nl}[(\mathrm{N}+1) / 2-\mathrm{S}] / \mathrm{N}$.

We first show that this expression is linear in $\mathrm{D}$ so that $\mathrm{U}^{\mathrm{W}}$ is maximized by either having the largest $\mathrm{D}$ possible or the smallest $\mathrm{D}$ possible. Taking the derivative of $\mathrm{U}^{\mathrm{W}}$ with respect to $\mathrm{D}$, we get:

$$
\mathrm{x}_{\mathrm{W}}-2 \mathrm{BC} \mathrm{x}_{\mathrm{W}}[(\mathrm{N}+1) / 2-\mathrm{S}] / \mathrm{N}=\mathrm{x}_{\mathrm{W}}[1-\mathrm{BC}[(\mathrm{N}+1-2 \mathrm{~S}] / \mathrm{N}] .
$$

For given values of $\mathrm{BC}, \mathrm{N}$ and $\mathrm{S}$, this derivative is either always positive or always negative (when $\mathrm{BC}>\mathrm{N} /[(\mathrm{N}+1-2 \mathrm{~S}])$. If the expression is always negative, then altruistic individuals will prefer $\mathrm{D}$ to be the smallest consistent with $\mathrm{Dx}_{\mathrm{W}} \geq \mathrm{Y} / \mathrm{N}$. That is, their highest utility would occur when they received Y/N; so, they would always prefer the perfect egalitarian distribution. Hence, if $\mathrm{BC} \geq \mathrm{N} /[(\mathrm{N}+1-2 \mathrm{~S}]$, then the egalitarian distribution is weakly preferred to any other.

$$
\text { q.e.d. }
$$

We can see immediately that the transitivity requirements for $\mathrm{BC}$ are greater than when there are no selfish individuals and $\mathrm{S}=0$.

So far, I have not explicitly considered candidate motivation. However, it should be clear from the propositions that if an equilibrium exists, it will be an equilibrium for candidates who only want to win as well as for candidates who have similar altruistic preferences as the voters. ${ }^{4}$

\section{DISCUSSION}

There is a significant body of work on positive theories of income distribution and redistribution when all of the voters are selfish (see, for example, work by Coughlin, 1986,

\footnotetext{
${ }^{4}$ However, I have not considered the case where the candidates have different preference functions from the voters.
} 
Lindbeck and Weibul, 1987, Wittman, 1989, and Bishop et. al., 1991). Unlike the analysis here, these papers have uncertainty built into their models -- even though the candidates believe that a voter is getting more from candidate $\mathrm{D}$ than from candidate $\mathrm{R}$, the voter may still vote for R. ${ }^{5}$ Given the appropriate assumptions, probability creates enough voting inertia to guarantee an equilibrium.

There is an even more extensive and varied literature on normative criteria for income distribution and welfare (see, for example, Atkinson, 1976, Chakravarty, 1990, Roemer, 1996, and Jorgenson, 1997).

In contrast, here, we have a positive theory of elections when some or all of the voters temper their selfish interests with some concern for the distribution of income. This combination of the positive theory of elections with normatively inclined voters is very rare, a major exception being Dixit and Londregan (1998). ${ }^{6}$ In their model, one candidate prefers higher average income, while the other candidate prefers a more equitable distribution. They assume that income redistribution is costly and that richer people on average prefer less redistribution than poorer people do. The candidates are uncertain about the election outcome and maximize expected plurality. In order to insure a pure-strategy equilibrium, the authors assume that the candidates' positions are not too close; they do this by assuming that the candidates themselves have strong preferences for the policies. Thus the model that I presented here is quite different because it does not assume probabilistic voting functions, preferences for equity being a function of the voter's pre-tax income, or taxes being uniform for people of similar pre-tax incomes. The results differ, as well. In particular, my model produces an egalitarian outcome when transfers are not costly, while in their model the median income voter gains the most. In my model, there is a clear demarcation between those parameter values that lead to a majority-rule equilibrium and those that produce intransitivity.

In the real-world, the costless transfers assumed in this model do not occur. For example, taxes and subsidies may discourage effort and GNP. Therefore, full equality may not be achieved even if voters are altruistic because the incentive effects on effort might drastically reduce the overall size of the pie. People are only mildly altruistic -- the rich are willing to be collectively taxed, but would prefer that the rest of the rich paid taxes and they personally avoided them. Because people are only mildly altruistic, the altruism benefit that a rich individual receives from her own taxes

\footnotetext{
5 The uncertainty may also be modeled as voter uncertainty (see especially, Bishop et. al.).

${ }^{6}$ Roemer (1999) considers the case where the political parties choose $\mathrm{A}, \mathrm{B}$, and $\mathrm{C}$ in the equation $\mathrm{A}^{2} \mathrm{X}+\mathrm{BX}+\mathrm{C}$, subject to a balanced budget constraint, where $\mathrm{X}$ is pre-tax income and the equation is post-tax income. For any given pair of platforms, the probability of a party winning is uncertain. The political parties are composed of reformists, militants and opportunists. The militants and opportunists have concerns for wealth distribution (e.g.,
} 
being redistributed to the poor does not compensate for the direct loss and so the person may choose to work less hard. That is, a million dollars taken from one rich person only increases the average by $\$ 1.00$ if there are a million poor people. While a rich person might agree to do this when there are 100,000 other rich people doing this as well, the rich person would still prefer that the 99,999 other rich people were contributing and the particular rich person was contributing not at all. As a result, when effort is voluntary, we would not see pure income equality even if everyone had altruism parameters $\mathrm{BC}>1$ because equality of income would reduce the size of the pie.

We have provided the critical values $(\mathrm{BC}>1$ and $\mathrm{C}<.5)$ such that $(1)$ altruism produces equality in a pure income redistribution world, and (2) the distaste for inequality is not so severe that a person might be against Pareto improving outcomes. But what kind of tradeoffs are implied by these parameters and how do these tradeoffs accord with our own sense of altruism?

First, consider the BY/N term. Suppose the following choice were presented to you: if your income were to go down by $\$ 10,000$ a year, then average income would go up by $\$ 1,000$ a year. Further assume that the overall variability in income does not change so that the $\mathrm{BC} \Sigma\left(\left|\mathrm{x}_{\mathrm{i}}-\overline{\mathrm{x}}\right|\right) / \mathrm{N}$ term remains constant. If you live in Italy, then your sacrifice of $\$ 10,000$ would result in an increase in per capita income of $\$ 1,000$ for approximately 60 million people. Now such a trade-off is unlikely, but if such a trade off were presented to you, would you be willing to take the sacrifice? If the answer is yes, then you weight $\mathrm{B}>10$.

Turning to the distribution term, suppose that total income remained constant, but that the richest 10 million Italians give $\$ 10,000$ to the poorest 10 million Italians. Then the $\Sigma\left(\left|\mathrm{x}_{\mathrm{i}}-\overline{\mathrm{x}}\right|\right) / \mathrm{N}$ term is reduced by $10000 / 3$ (as 20 million out of 60 million Italians are affected). If you would be willing to sacrifice $\$ 10,000$ to collectively achieve this outcome, then this means that for you BC > 3.

If you were the only rich Italian doing this, then the $\Sigma\left(\left|x_{i}-\bar{x}\right|\right) / N$ term would be reduced by only 10,000/30,000,000 (as only the equivalent of 2 out of 60 million Italians are affected by $\$ 10,000)$. To do this on your own would require BC to be greater than $30,000,000$. Essentially, the requirement for a collectively altruistic act is much smaller than the requirement for an individually altruistic act.

they want to help those with low pre-tax income), but each voter is solely concerned with her own post-tax income. Thus Roemer's model is quite different from the model considered here 
"Selfish" individuals can choose to be collectively altruistic. 


\section{REFERENCES}

Bishop, John A., Formby, John P. and James W. Smith (1991) "Incomplete Information, Income Redistribution and Risk Averse Median Voter Behavior" Public Choice 68: 41-55.

Chakravarty, Satya R. (1990) Ethical Social Index Numbers New York: Springer.

Coughlin, Peter J. (1986) “Elections and Income Redistribution” Public Choice 50: 27-91.

Dixit, Avinash and John Londregan (1998) "Ideology, Tactics, and Efficiency in Redistributive Politics" Quarterly Journal of Economics 113: 497-529.

Goodin, Robert E. (1988) Reasons for Welfare, Princeton University Press.

Hochman, Harold M. and James Rodgers (1969) Pareto Optimal Redistribution, American Economic Review 59: 542-547.

Jorgenson, Dale W. (1997) Welfare Volume 2. Measuring Social Welfare Cambridge: MIT Press.

Lindbeck, Assar and Jorgen Weibull (1987) "Balanced budget redistribution as the outcome of political competition" Public Choice 52: 273-297

Roemer, John E. (1996) Theories of Distributive Justice Cambridge: Harvard University Press.

Roemer, John E. (1999) “The Democratic Political Economy of Progressive Income Taxation” Econometrica 67: 1-19.

Ward, Benjamin (1961) "Majority Rule and Allocation," Journal of Conflict Resolution 5:379389.

Wittman, Donald A. (1989) "Pressure Group Size and the Politics of Income Redistribution" Social Choice and Welfare 6: 275-86. 